\title{
CHANGES IN EATING BEHAVIOURS FOLLOWING BARIATRIC SURGERY: A PROSPECTIVE STUDY
}

\section{Kavitha Subramaniam ${ }^{* 1,2}$, Wah-Yun Low ${ }^{3}$, Peng-Choong Lau ${ }^{4}$, Kin-Fah Chin ${ }^{4}$, Karuthan Chinna ${ }^{5}$, Nik Ritza Kosai ${ }^{6}$, Mustafa Taher ${ }^{6}$, Reynu Rajan $^{6}$}

${ }^{1}$ Medical Education, Research and Development Unit, Faculty of Medicine, University of Malaya, Malaysia

${ }^{2}$ Department of Physical and Mathematical Science, Universiti Tunku Abdul Rahman, Jalan Universiti, Bandar Barat, 31900, Kampar, Malaysia

${ }^{3}$ Dean's Office, Faculty of Medicine, University of Malaya, Malaysia

${ }^{4}$ Department of Surgery, Faculty of Medicine, University of Malaya, Malaysia

${ }^{5}$ School of medicine, Faculty of Medical and Health Science, Taylor's, University Malaysia

${ }^{6}$ Minimally Invasive, Upper gastrointestinal and bariatric surgery, Department of Surgery, Faculty of Medicine, University Kebangsaan Malaysia.

Received - July 18, 2020; Revision - September 17, 2020; Accepted - November 07, 2020

Available Online - March 25, 2021

DOI: http://dx.doi.org/10.18006/2021.9(Spl-1-GCSGD 2020).S101.S109

$$
\begin{aligned}
& \text { Keywords } \\
& \text { Eating Behaviour } \\
& \text { Emotional Eating } \\
& \text { External Eating } \\
& \text { Bariatric Surgery } \\
& \text { Diabetes }
\end{aligned}
$$

\section{ABSTRACT}

Adopting healthy eating behavior is important in achieving successful weight loss after bariatric surgery. This study aims to determine the changes in eating behaviors 6 months after surgery. Fifty-seven patients who went through bariatric surgery in two tertiary referral hospitals were recruited and interviewed before surgery (T0), three (T1), and six (T2) months after surgery. Eating behaviors were assessed using the Dutch Eating Behavior Questionnaire (DEBQ), which measured emotional, external, and restrained eating. Higher subscale scores indicate strong behavioral traits. Other information including psychological distress, quality of life, socio-demography, and morbidity were collected. Generalized Estimating Equation (GEE) model was developed to study the change in eating behaviors and its' predictors over time. Participants of the study were mostly women, from the Malay ethnic group and the average age at the time of surgery was 39.4 years. Emotional and external eating scores changed significantly over time with the values recorded at various time intervals as follows: 2.06 and 2.86 before surgery; 1.64 and 2.25 three months after surgery; and 1.81 and 2.40, 6 months after surgery. Reduction in the third month followed by a slight increase at the sixth was noted. Restrained eating did not show a significant change. The presence of diabetes was also associated with higher emotional and external eating scores. Further, higher anxiety scores were associated with higher external eating. Favorable changes in eating behaviors were noted after bariatric surgery. However, a risk of a reversal in the improvement was present. The emotional and external eating behaviors in surgical candidates should be identified and addressed accordingly with special attention to diabetic patients.
\end{abstract}

\section{* Corresponding author}

E-mail:eskei13@yahoo.co.uk, kavithas@utar.edu.my (Kavitha Subramaniam)

Peer review under responsibility of Journal of Experimental Biology and Agricultural Sciences.

Production and Hosting by Horizon Publisher India [HPI] (http://www.horizonpublisherindia.in/).

All rights reserved.

All the articles published by Journal of Experimental Biology and Agricultural Sciencesare licensed under a Creative Commons Attribution-NonCommercial 4.0 International License Based on a work at www.jebas.org.

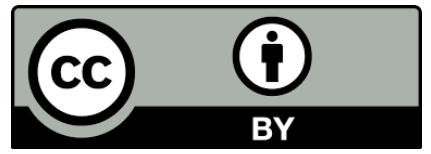




\section{Introduction}

To date, bariatric surgery is the most durable weight-loss solution for patients with morbid obesity (Carter, 2015). Post-surgically, patients lose up to $60 \%$ of excess weight (Coleman et al., 2014), and $85 \%$ of the patients were able to maintain $50 \%$ of the excess weight loss (Madura \& Dibaise, 2012). Despite the promising overall outcome, individual variations in the post-surgical weight loss achievement have been reported, where some patients experienced sub-optimal weight loss (Campos et al., 2009; Conceição \& Goldschmidt, 2019; Geerts et al., 2020) and some regained weight (Odom et al., 2010; Baig et al., 2019; Conceição \& Goldschmidt, 2019). Surgical patients who practiced healthy lifestyles, which include controlled eating and regular physical exercise had better post-surgical weight loss (Madura \& Dibaise, 2012; Monpellier et al., 2019). Conducive eating behaviour for better weight loss outcomes included adherence to dietary recommendations given by health professionals (Robinson et al., 2014) and having controlled food urges (Odom et al., 2010). Postoperative disordered eating behaviours such as binge eating (Luiz et al., 2016; Conceição \& Goldschmidt, 2019), grazing (Wimmelmann et al., 2014; Pinto-Bastos et al., 2019) night eating (Wimmelmann et al., 2014), emotional eating (Chesler, 2012; Novelli et al., 2017; Conceição \& Goldschmidt, 2019) and loss of control eating (White et al., 2010; Geerts et al., 2020) were associated with poor weight loss outcomes.

The surgical option for weight loss is often provided to patients with morbid obesity, who had futile efforts to lose weight via the conventional treatment. Previous failed attempts to lose weight lead patients to think that obesity and the eating behaviours are beyond their ability to control (da Silva \& Maia, 2012; Opolski et al., 2015) and weight-loss surgery is seen as a "miracle moment" that is to happen to them, which is as an external solution that will help them to change their lifestyle without any effort from themselves (da Silva \& Maia, 2012). Such understanding is of concern, as previous findings have reported high rates of disordered eating behaviour traits, such as emotional eating, binge eating, binge eating disorder, and food craving among the surgical candidates (Opolski et al., 2015), that continued to exist postsurgically in some patients (White et al., 2010; Conceição et al., 2014; Nasirzadeh et al., 2018; Conceição \& Goldschmidt, 2019;), resulting in poor weight loss outcome (White et al., 2010; Chesler, 2012; Wimmelmann et al., 2014; Luiz et al., 2016; Novelli et al., 2017; Nasirzadeh et al., 2018). Controlled eating after bariatric surgery is pertinent for weight loss, weight maintenance, and the overall well-being of the patients. Knowledge of predictors of changes in eating behaviour among bariatric surgery candidates is very limited. Such knowledge will be helpful for patient-care to achieve adequate weight loss and health. This study was thus designed to identify the changes in disordered eating behaviors from pre to six months post-surgery and identify demographic and psychological predictors of changes in eating behaviors.

\section{Materials and Methods}

\subsection{Selection of participants and Data Collection}

Fifty-seven bariatric surgery candidates from two referral hospitals in Kuala Lumpur were recruited upon written consent. The participants were assessed at three timelines, before surgery (T0), three (T1), and six (T2) months after surgery. Forty-five participants (79\%) turned up for the second interview (T1), and 43 (75\%) turned up for the third interview (T2). Thirty-six participants $(63 \%)$ completed all three follow-ups. The surgeries performed on the patients were Laparoscopic Roux-en-Y gastric bypass (LRYGB) $(\mathrm{n}=30,53 \%)$, Laparoscopic sleeve gastrectomy (LSG) $(n=23,40 \%)$, and one anastomosis mini gastric bypass (OAMGB) $(\mathrm{n}=4,7 \%)$.

\subsection{Assessments}

This study is part of a larger research that aimed to determine the changes in health-related quality of life, psycho-behavioural variables, sexual function, and weight loss following bariatric surgery. Changes in eating behaviour are discussed in this study. Eating behavioural traits were assessed with the aid of the Dutch Eating Behaviour Questionnaire (DEBQ)(Van Strien et al., 1986). The DEBQ instrument consists of 33 items that assess three eating behaviours viz., (i) emotional eating, that is, eating in response to emotional cues or to regulate emotion; (ii) external eating, that is, eating in response to external food-related cues such as sight and smell of food; and (iii) dietary restraint (restrained eating), that is, dietary control via cognitive cues to influence one's body weight (Van Strien et al., 1986). A higher mean score for each subscale denotes a stronger behavioural trait. The DEBQ instrument has satisfactory construct validity and internal consistency when tested on the Malaysian adult sample (Subramaniam et al., 2017). Emotional, external, and restrained eating behaviours were included in this study as the behaviours were associated with eating disorders that are common among adults with obesity such as disinhibition, binge eating, night eating, and food addiction (Chesler, 2012; Nolan \& Geliebter, 2012; Dochat et al., 2019).

Participants were screened for anxiety and depression using the Hospital Anxiety and Depression Scale (HADS) (Zigmond \& Snaith, 1983). The anxiety subscale score of 7-9 indicates possible anxiety, 10-13 indicate probable anxiety, and 14 and above for severe anxiety. The depression subscale score of $8-10$ indicates possible depression, 11-14, indicates probable depression, and 15 and above, severe depression (Zigmond \& Snaith, 1983). The HADS instrument was reported to be suitable to be used in the Malaysian population (Quek et al., 2007). The possible, probable, 
and severe anxiety and depression were combined to form the clinically significant anxiety and clinically meaningful depression categories due to small sample sizes.

The health related quality of life (HRQoL) was measured using the Short-Form 36 (SF 36) instrument (Ware \& Sherbourne, 1992). The SF-36 contains 36 items that assess 8 dimensions of health, namely physical functioning, role limitations due to physical problems (termed 'role physical'), bodily pain, general health, vitality, social functioning, role limitations due to emotional problems (termed 'role emotional') and mental health. Each subscale score ranges from 0-100 with higher scores indicating better health status. The subscales are further grouped to obtain a composite score for physical health (Physical Component Score, PCS) and mental Health (Mental Component Score, MCS). The instrument showed good structural validity and reliability (Chronbach's alpha value above 0.7 for all subscales with exception to SF, which had a value of 0.62 ) when tested on the general Malaysian population (Sararaks et al., 2005) and thus it is a suitable measure of HRQOL for the Malaysian population (Sararaks et al., 2005).

Basic socio-demographic information such as gender, age, ethnicity, marital status, and occupation were collected. Several personal and family health indicators were assessed during the interview, which includes the following: duration of obesity (childhood or later), presence of overweight or obese family members, and incidence of comorbidities among first-degree family members. Information about the presence of obesity-related comorbidities such as diabetes, hypertension, dyslipidemia, fatty liver disease, sleep apnoea, and conditions that cause difficulty in walking was recorded from the patients' medical records.

The height and weight of the participants were measured during all three follow-up sessions using the standard hospital scales and rounded to the nearest $0.1 \mathrm{~cm}$, and $0.1 \mathrm{~kg}$. Body Mass Index (BMI) was estimated in the mathematical format of (weight, $\mathrm{kg}$ )/(height, m)2. Total weight loss (TWL) \% was estimated in the mathematical format of [(preoperative weight - postoperative weight/ preoperative weight)] X 100\%. Excess BMI loss (EBMIL)was estimated in the mathematical format of [(Pretreatment BMI-current BMI)/ ((pre-treatment BMI- 25)] X 100\%.

\subsection{Compliance with Ethical Standard}

Ethics approval was obtained from both hospitals' ethics committees (First hospital: MEC Ref No 732.19; Second Hospital: JEP-2016-276). This study is research involving human participants. All participants were recruited in the study upon written informed consent.

\subsection{Statistical Analysis}

Characteristics of the groups studied at each timeline was compared to determine if the groups that were followed-up were the same as the original recruited group at T0. Chi-square test was conducted to compare the categorical variables whereas the Kruskal-Wallis test was conducted to compare the distribution of continuous variables. Friedman's test was conducted to study the change in the distribution of variables over time. Wilcoxon signrank test with Bonferroni's adjustment was the post-hoc test conducted. Kendall's W test was used as the effect size where a value 0.1 indicates a small effect size, 0.3 moderate and 0.5 and above a indicates large effect. Spearman's rank correlation coefficient was used to study the relationship between variables. The Generalised Estimating Equation (GEE), was used to study the changes in eating behaviour over time, and predictors of change, if any. The GEE technique does not exclude incomplete cases from the analysis, and it produces findings based on all available data. It also does not require the normality assumption (Naseri et al., 2016). Pre-surgical and time-varying factors were included as predictors of changes in eating behaviour. The pre-surgical factors tested in the model were age, gender, ethnicity, marital status, initial BMI, and baseline comorbidities. Time-varying factors studied were psychological distress, HRQoL, surgery-related complications at follow-ups, and longitudinal BMI. Statistically significant variables $(\mathrm{p}<0.05)$ that improved the overall fit of the model were retained in the final regression equation.

\section{Results}

\subsection{Socio-demographic characteristics and weight loss}

A total of 57 bariatric surgery patients participated in the study, of whom 45 (79\%) turned for the third-month assessment and 43 (75\%) turned up for the sixth-month assessment. As the follow-up rates below $80 \%$ are a concern, the characteristics of the participant group included in each timeline were compared to determine if they were similar to the initial group recruited. The socio-demographic and initial weight (baseline weight) characteristics of the participants did not differ across time. The sub-group studied is not different from the original group recruited and the findings from follow-up data could be used to generalise for the included participants (Table 1). Little's Missing completely at random (MCAR) test was conducted to determine if the missing pattern was MCAR. The MCAR test was conducted across all timeline together $\left(x^{2}=12.78, \mathrm{p}=0.17\right)$, only $\mathrm{T} 1$ data $\left(x^{2}=3.16\right.$, $\mathrm{p}=0.37)$ and only $\mathrm{T} 2$ data $\left(\chi^{2}=9.55, \mathrm{p}=0.48\right)$. It was found that the missing pattern was MCAR in all the comparisons. The missing pattern analysis shows that the assumption needed for the regression analysis is fulfilled. The MCAR missing pattern confirms that the missingness is not dependent on any variables or outcome. 
Table 1 Socio-demographic characteristics and baseline anthropometric measures of the participants included at $T_{0}, T_{1}$ and $T_{2}$

\begin{tabular}{|c|c|c|c|}
\hline Characteristics & $\begin{array}{c}\text { Participants at } \mathrm{T}_{0} \\
(\mathrm{n}=57) \\
\mathrm{n}(\%)\end{array}$ & $\begin{array}{c}\text { Participants at } \\
\mathrm{T}_{1} \\
(\mathrm{n}=45) ; \mathrm{n}(\%)\end{array}$ & $\begin{array}{c}\text { Participants at } \mathrm{T}_{2} \\
(\mathrm{n}=43) \\
\mathrm{n}(\%)\end{array}$ \\
\hline Gender & & & \\
\hline Female & $37(65.0)$ & $29(64.4)$ & $27(62.8)$ \\
\hline Male & $20(35.0)$ & $16(35.6)$ & $16(37.2)$ \\
\hline \multicolumn{4}{|l|}{ Age (Years) $\dagger$} \\
\hline Mean, (sd) & $39.40,(10.01)$ & $38.18(9.79)$ & $40.19(10.13)$ \\
\hline Median, (IQR) & $39.00,(12.00)$ & $36.00(12.5)$ & $40.0(14.0)$ \\
\hline \multicolumn{4}{|l|}{ Ethnicity } \\
\hline Malay & $43(75.4)$ & $36(80.0)$ & $33(76.7)$ \\
\hline Indians & $10(17.5)$ & $8(17.8)$ & $(14.0)$ \\
\hline Chinese and Others & $4(7.0)$ & $1(2.2)$ & $4(9.4)$ \\
\hline \multicolumn{4}{|l|}{ Marital Status } \\
\hline Married & $47(82.0)$ & $36(80.0)$ & $37(86.0)$ \\
\hline Single / widower/ widowed & $10(18.0)$ & $9(20.0)$ & $6(14.0)$ \\
\hline \multicolumn{4}{|l|}{ Educational Qualification } \\
\hline Primary/Secondary & $18(31.6)$ & $13(28.9)$ & $14(32.5)$ \\
\hline College & $13(22.8)$ & $11(24.4)$ & $10(23.3)$ \\
\hline University & $26(45.6)$ & $21(46.7)$ & $19(44.2)$ \\
\hline \multicolumn{4}{|l|}{ Housing situation } \\
\hline Own House & $47(82.5)$ & $35(77.8)$ & $36(83.7)$ \\
\hline Rented House/ Quarters / others & $10(17.5)$ & $10(22.2)$ & $7(16.3)$ \\
\hline \multicolumn{4}{|l|}{ Mode of transport } \\
\hline Own transport & $52(91)$ & $41(91.1)$ & $39(90.7)$ \\
\hline Public transport/ Others & $5(9)$ & $4(8.9)$ & $4(9.3)$ \\
\hline Weight $($ mean $\pm \mathrm{sd})$ & $123.07 \pm 33.0$ & $120.36 \pm 34.88$ & $125.36 \pm 34.30$ \\
\hline $\mathrm{BMI}($ mean $\pm \mathrm{sd})$ & $45.46 \pm 9.93$ & $44.72 \pm 10.47$ & $46.24 \pm 10.21$ \\
\hline
\end{tabular}

sd - standard deviation, Ethnicity comparison was made by combining Indians and Chinese and others in one category, the Non-Malay group. The Malay and Non-Malay group were compared. Chisquare-test was conducted to compare categories; Kruskal-Wallis test was conducted to compare the weight and BM across the three groupsI.*p<0.05, $* * \mathrm{p}<0.01$.

The majority of the participants were Malays and women. The mean age of the participants was $39.40 \quad(\mathrm{SD}=10.01)$ years and an average initial BMI of $45.52(\mathrm{SD}=9.94)$ (Table 1). The mean TWL achieved at the third and sixth months were $22.28 \%(\mathrm{SD}=7.82)$ and $23.83 \%(\mathrm{SD}=7.40)$ respectively. The mean EBMIL achieved at the third and sixth months were $40.55 \% \quad(\mathrm{SD}=18.33)$ and $63.33 \% \quad(\mathrm{SD}=33.18)$ respectively.

The most pronounced weight loss occurred in the first three months. The baseline prevalence of co-morbidities was as follow: diabetes (47\%); hypertension (37\%); dyslipidemia (35\%); obstructive sleep apnoea (21\%); fatty liver (7\%), and problems affecting mobility (such as knee pain) was $21 \%$. Family support during the time of illness was assessed with one question, "Who usually takes care of you if you become ill?" The majority of the participants $(n=34,60 \%)$ stated that their spouses took care of them when they were ill, followed by parents $(n=8,14 \%)$, children $(\mathrm{n}=3,5 \%)$, and siblings $(\mathrm{n}=2,3.5 \%)$. The remaining10 participants
$(17.5 \%)$ stated that they took care of themselves. No one stated that they were taken care of by a non-family member.

\subsection{Psychological distress}

The mean and median anxiety and depression scores reduced over time with a moderate effect size. This was accompanied by a reduction in the prevalence of clinically meaningful anxiety and depression across the study. A significant change in anxiety score was noted between the $\mathrm{T} 0$ and $\mathrm{T} 2$ timelines whereas a significant reduction in depression was noted from $\mathrm{T} 0$ to $\mathrm{T} 1$ and $\mathrm{T} 0$ to $\mathrm{T} 2$ (Table 2).

\subsection{Health Related Quality of Life}

The mean and median physical component summary scores increased over time. Post-hoc comparison showed that there was a significant improvement across all timelines with a large effect size (Table 2). The Mental component summary scores improved across time with a small effect size. Significant improvements were noted between $\mathrm{T} 0$ to $\mathrm{T} 1$ and $\mathrm{T} 0$ to $\mathrm{T} 2$ timelines (Table 2). 
Table 2 Distribution of eating behaviour and psychological distress across study duration

\begin{tabular}{|c|c|c|c|c|c|}
\hline Factor & $\mathbf{T}_{\mathbf{0}}$ & $\begin{array}{c}\text { Timeline } \\
\mathbf{T}_{\mathbf{1}}\end{array}$ & $\mathbf{T}_{2}$ & $\chi^{2}, \mathrm{p} *$ & Effect Size \\
\hline $\begin{array}{c}\text { Emotional Eating } \\
\text { Mean, (sd) } \\
\text { Median,(IQR) }\end{array}$ & $\begin{array}{l}2.06,(0.94) \\
1.73,(1.44)\end{array}$ & $\begin{array}{l}1.64,(0.80) \\
1.23,(1.13)\end{array}$ & $\begin{array}{l}1.81,(0.81) \\
1.58,(1.00)\end{array}$ & $\begin{array}{c}3.928 \\
p>0.05\end{array}$ & 0.082 \\
\hline $\begin{array}{l}\text { External Eating } \\
\text { Mean, (sd) } \\
\text { Median, (IQR) }\end{array}$ & $\begin{array}{l}2.86,(0.68) \\
2.80,(0.80)\end{array}$ & $\begin{array}{l}2.25,(0.79) \\
2.10,(1.53)\end{array}$ & $\begin{array}{l}2.40,(0.68) \\
2.30,(0.93)\end{array}$ & $\begin{array}{l}17.156^{\mathrm{ac}} \\
\mathrm{p}<0.01\end{array}$ & 0.378 \\
\hline $\begin{array}{c}\text { Restrained Eating } \\
\text { Mean, (sd) } \\
\text { Median, (IQR) }\end{array}$ & $\begin{array}{l}2.65,(0.73) \\
2.70,(0.90)\end{array}$ & $\begin{array}{l}2.93,(0.86) \\
2.90,(1.48)\end{array}$ & $\begin{array}{l}2.74,(0.77) \\
2.80,(1.13)\end{array}$ & $\begin{array}{c}3.489 \\
\mathrm{p}>0.05\end{array}$ & 0.027 \\
\hline $\begin{array}{c}\text { Anxiety } \\
\text { Mean, (sd) } \\
\text { Median, (IQR) } \\
\text { Rate n (\%) }\end{array}$ & $\begin{array}{c}4.88,(3.23) \\
4.00,(5.0) \\
12(21.0)\end{array}$ & $\begin{array}{c}3.43,(2.94) \\
3.00,(4.00) \\
4(7.0)\end{array}$ & $\begin{array}{c}2.40,(2.47) \\
2.00,(4.00) \\
2(3.5)\end{array}$ & $\begin{array}{l}32.53^{\mathrm{c}} \\
\mathrm{p}<0.01\end{array}$ & 0.465 \\
\hline $\begin{array}{c}\text { Depression } \\
\text { Mean, (sd) } \\
\text { Median, (IQR) } \\
\text { Rate } \mathrm{n}(\%)\end{array}$ & $\begin{array}{c}3.72,(2.89) \\
3.00,(5.00) \\
4(7)\end{array}$ & $\begin{array}{c}2.02,(2.59) \\
1.00,(2.00) \\
3(5.3)\end{array}$ & $\begin{array}{c}1.60,(2.13) \\
1.00,(3.00) \\
1(1.8)\end{array}$ & $\begin{array}{l}28.82^{a c} \\
p<0.01\end{array}$ & 0.412 \\
\hline HRQoL-PCS & & & & & \\
\hline Mean,(sd) & $42.77,(8.96)$ & $49.85,(6.87)$ & $51.59,(7.88)$ & $39.31^{\mathrm{abc}}$ & 0.546 \\
\hline Median, (IQR) & $45.11,(14.25)$ & $51.23,(10.44)$ & $53.11,(7.96)$ & $\mathrm{p}<0.01$ & \\
\hline HRQoL-MCS & & & & & \\
\hline Mean, (sd) & $50.19,(8.98)$ & $53.90,(8.57)$ & $54.79,(7.82)$ & $7.26^{\mathrm{ac}}$ & 0.101 \\
\hline Median, (IQR) & $50.53,(10.67)$ & $57.37,(10.51)$ & $56.73,(9.95)$ & $\mathrm{p}<0.05$ & \\
\hline
\end{tabular}

HRQoL-Health Related Quality of Life, PCS-Physical Component Summary, MCS- Mental Component Summary, *Friedman's test, sd-standard deviation, IQR- Inter Quartile Range. Prevalence of clinically significant anxiety and depression are reported below mean scores. $T_{0^{-}}$before surgery $T_{1}$-Three months after surgery $T_{2}$-Six months after surgery, a-significant difference between $\mathrm{T}^{0}$ and $\mathrm{T}^{1}$, b-significant difference between $\mathrm{T}^{1}$ and $\mathrm{T}^{2}$, c-significant difference between $\mathrm{T}^{0}$ and $\mathrm{T}^{2}$.

\subsection{Eating Behaviours}

The scores of emotional and external eating behaviours decreased from the baseline to $\mathrm{T} 1$ but increased at $\mathrm{T} 2$.

On the other hand, the score of restrained eating increased at $\mathrm{T} 1$ and decreased at T2. Friedman's test outcomes showed that only external eating changed over time. Post-hoc comparison showed that the scores reduced significantly from $\mathrm{T} 0$ and $\mathrm{T} 1$ and $\mathrm{T} 0$ and T2. In the GEE analysis, emotional and external eating scores changed in the six months, whereas the restraint eating did not (Table 3).

The GEE analysis does not exclude incomplete cases and is thus deemed to be a more robust analysis. The emotional eating score changed at the rate of $-0.32 t+0.79 t^{2}$ per month. The positive term for the squared variables shows a minimum point. The presence of diabetes is associated with a higher emotional eating score.

The external eating score changes at the rate of $-0.38 t+0.06 t^{2}$ per month. Higher anxiety scores and the presence of diabetes were associated with increased external eating scores. Demographic, socio-economic, comorbidity, and HRQoL variables were not associated with a change in emotional and external eating scores across time.

\section{Discussion}

This study was aimed to identify the pattern of changes in eating behaviours post-surgery and predictors of changes in eating behaviours. Emotional and external eating changed significantly over time. The reduction in emotional and external eating scores at the 3rdand 6th post-surgical months echoed previous findings which reported score reduction in uncontrolled eating (Laurenius et al., 2012) and emotional eating (van Hout et al., 2007) at the 6th week and 6th month after surgery. Both the authors found the improvements to have waned off during one and two year followups (van Hout et al., 2007; Laurenius et al., 2012).

Recent finding with longer follow-up intervals showed that mean emotional, external, and restrained eating scores showed maximum 
Table 3 Predictors of changes in emotional and external eating across study duration

\begin{tabular}{|cc|}
\hline Factor & Regression coefficient $\beta$ (95\% Confidence Interval of $\beta$ ) \\
\hline Emotional Eating & $1.71(1.39,2.04)$ \\
\hline Intercept & $-0.32(-0.52,-0.12)$ \\
\hline Time (month) & $0.79(0.05,1.52)$ \\
\hline Time ${ }^{2}$ (month) & $0.79(0.05,1.52)$ \\
\hline Diabetes & 0.00 \\
\hline Yes & \\
\hline No $\dagger$ & $2.30(2.00,2.61)$ \\
\hline Intercept & $-0.38(-0.54,-0.22)$ \\
\hline Time (month) & $0.06(0.02,0.10)$ \\
\hline Time ${ }^{2}($ month) & $0.06(0.01,0.10)$ \\
\hline Anxiety & $0.70(0.15,1.25)$ \\
\hline Diabetes & \\
\hline Yes & \\
\hline No $\dagger$ & \\
\hline
\end{tabular}

$\dagger$-reference category

reduction at the 15 th month after surgery, followed by an increase at the 24th and 36th, and 48th months (Monpellier et al., 2019).Another study showed that binge eating, emotional eating, and loss of control eating behaviours reduced one year after surgery, and increased thereafter at the second and third postsurgical years (Nasirzadeh et al., 2018). The increasing trend at a shorter follow-up duration of sixth-month post-surgery noted in the current study is in coherence with the previous finding which showed that disordered eating behavioursre-emerged as early as 49 months after bariatric surgery (Conceição \& Goldschmidt, 2019).

Further research with longer study duration and shorter follow-up intervals is needed to obtain a more precise picture of the improvement in emotional and external eating disorders over time. An important fact highlighted by all these studies is that there is a clear possibility of the improvement in eating behaviour achieved after the surgery waning off with time. Post-surgical disordered eating behaviour traits have a negative impact on weight loss (White et al., 2010; Konttinen et al., 2015; Nasirzadeh et al., 2018; Conceição \& Goldschmidt, 2019; Monpellier et al., 2019). Thus, in addition to the surgery induced anatomical change that reduced the eating capacity, behavioural change in the patients is also needed to optimize the benefit of bariatric surgery. Monitoring and addressing the negative eating behavioural traits at the early phase are necessary to achieve the desired weight loss outcome in the long term. Further research on effective interventions for disordered eating behaviour among bariatric surgery candidates is warranted.

Diagnosis with diabetes was found to be associated with higher emotional and external eating scores. A review reported that the prevalence of disordered eating was as high as $40 \%$ among patients with diabetes, with binge eating and night eating syndrome being the most common (García-mayor \& García-soidán, 2016). Another study that recruited diabetes patients and healthy controls showed that diabetes patients had a much higher rate of binge eating and disordered eating than healthy controls (Nicolau et al., 2015). As almost half of the surgical patients in the current study (47\%) have been diagnosed with diabetes, the association between emotional and external eating with baseline diabetes could be reflecting the previous findings on the association between diabetes and disordered eating. This is something that warrants attention as among the diabetic patients, disordered eating were associated with poor triglyceride levels (Nicolau et al., 2015), poor metabolic controls (García-mayor \& García-soidán, 2016), and diabetic complications (García-mayor \& García-soidán, 2016). Bariatric surgery patients who were diagnosed with diabetes were reported to achieve lower weight loss outcomes (Barr et al., 2019).

Previous studies reported remission and improvement of diabetes following bariatric surgery (Sjostrom, 2013; Sillén et al., 2017). The current finding shows that at the early stage after surgery, the diabetic group had unhealthy eating habits which might directly affect weight loss and indirectly the benefits of weight loss including remission of diabetes. Future studies should investigate if eating disorders cause poor metabolic controls among the surgical candidates with diabetes, like that reported for the clinical diabetic population, and also if the disordered eating behaviors affect the chances of diabetes remission.

Anxiety was found to be associated with the increased external eating score. The association between psychopathology and disordered eating behaviors in bariatric patients have been shown by previous researchers. Higher emotional and external eating 
scores were associated with higher depression scores (Sevinc et al., 2016). Emotional eating was found to partially mediate the relationship between body image dissatisfaction and depression and fully mediate the association between body image dissatisfaction and suicidality (Geller et al., 2019).

Bariatric surgery patients with food addiction, a type of disordered eating behaviour, was found to have a higher rate of current anxiety disorders and lifetime major depressive disorders (Benzerouk et al., 2018). The presence of disordered eating behaviours could have affected the patient's mental well-being and similarly, the patients could have succumbed to unhealthy eating behaviours due to underlying psychopathology. The mental wellbeing of the surgical candidates should be monitored regularly and new conditions or re-emerging conditions should be treated.

This study has some limitations. Firstly, the low follow-up rate is a concern, despite the follow-up samples having the same demographic characteristics as the baseline group. Secondly, the study was conducted in only two centers located in the capital of the country, and thus may not be representative of the bariatric surgery patients in suburban and rural settings. The post-surgical biomedical assessments were not standardised across institutions and thus the blood glucose level could not be assessed across time. Consequently, it could not be concluded whether the improvement in diabetes at the post-surgical timeline was influenced by disordered eating. The self-rated instruments, despite the established validity, impose the possibility of over or underreporting symptoms. Despite these limitations, this study provides information on factors that influence the change in eating behaviours post-surgery, an area that had not been well explored.

\section{Conclusion}

Emotional and external eating reduced from pre to three months post-surgery but increased thereafter to a level that was lower than baseline. This shows the possibility of reversal of the improvements after six-months. Baseline diabetes was associated with higher emotional and external eating at follow-ups. The disordered eating behaviors among surgical candidates should be monitored and addressed accordingly with special attention to the ones with comorbid diabetes. Future researches that have a longer study duration and include semi-urban and rural patients are warranted.

\section{Acknowledgement}

This study is funded by the University of Malaya via the postgraduate research fund (Grant no: PV122-2012A). We would like to record our appreciation for all the support and cooperation given to us by the University Malaya Medical Centre and University Kebangsaan Malaysia Medical Centre.

\section{References}

Baig S, Priya P, Mahawar K, Shah S (2019) Weight Regain After Bariatric Surgery-A Multicentre Study of 9617 Patients from Indian Bariatric Surgery Outcome Reporting Group. Obesity Surgery 29: $1583-1592$.

Barr ML, Tabone LE, Cox SJ, Brode C, Szoka N, Olfert IM, Davisson L, Olfert MD (2019) Bariatric Surgery Outcomes in Appalachia Influenced by Surgery Type, Diabetes, and Depression. Obesity Surgery 29 (4): 1222-1228.

Benzerouk F, Gierski F, Ducluzeau PH, Bourbao-Tournois C, Gaubil-Kaladjian I, Bertin É, Kaladjian A, Ballon N, Brunault P (2018) Food addiction, in obese patients seeking bariatric surgery, is associated with higher prevalence of current mood and anxiety disorders and past mood disorders. Psychiatry Research 267(November 2017): 473-479.

Campos GM, Rabl C, Mulligan K, Posselt A, Rogers SJ, Westphalen AC, Lin F (2009) Factors associated with weight loss after gastric bypass. Archives of Surgery 143(9): 877-884.

Carter PL (2015) The evolution of bariatric surgery. The American Journal of Surgery 209: 779-782.

Chesler BE (2012) Emotional eating: a virtually untreated risk factor for outcome following bariatric surgery. The Scientific World Journal : 365961.

Coleman KJ, Huang Y, Hendee F, Watson HL, Casillas RA, Brookey J (2014) Three-year weight outcomes from a bariatric surgery registry in a large integrated healthcare system. Surgery for Obesity and Related Diseases 10(3): 396-403.

Conceição EM, Goldschmidt A (2019) Disordered eating after bariatric surgery: Clinical aspects, impact on outcomes, and intervention strategies. Current Opinion in Psychiatry 32(6): 504509.

Conceição E, Mitchell JE, Vaz AR, Bastos AP, Silva C, Cao L, Brandão I, Machado PPP (2014) The presence of maladaptive eating behaviors after bariatric surgery in a cross sectional study: Importance of picking or nibbling on weight regain. Eating Behaviors 15: 558-562. https://doi.org/10.1016/j.eatbeh.2014.08.010

da Silva SSP, Maia AC (2012) Obesity and Treatment Meanings in Bariatric Surgery Candidates: A Qualitative Study. Obesity Surgery 22:1714-1722.

Dochat C, Godfrey KM, Golshan S, Cuneo JG, Afari N (2019) Dietary restraint and weight loss in relation to disinhibited eating 
in obese Veterans following a behavioral weight loss intervention Appetite 140(May): 98-104.

García-mayor RV, García-soidán FJ (2016) Eating disoders in type 2 diabetic people: Brief review. Diabetes \& Metabolic Syndrome: Clinical Research \& Reviews 11(3): 221-224.

Geerts MM, van den Berg EM, van Riel L, Peen J, Goudriaan JE, Dekker JJM (2020) Behavioral and psychological factors associated with suboptimal weight loss in post-bariatric surgery patients. Eating and Weight Disorders 2020:May 29.

Geller S, Levy S, Goldzweig G, Hamdan S, Manor A, Dahan S, Rothschild E, Stukalin Y, Abu-Abeid S (2019) Psychological distress among bariatric surgery candidates: The roles of body image and emotional eating. Clinical Obesity 9(2): e12298.

Konttinen H, Peltonen M, Sjöström L, Carlsson L, Karlsson J (2015) Psychological aspects of eating behavior as predictors of 10 -y weight changes after surgical and conventional treatment of severe obesity: results from the Swedish. The American Journal of Clinical Nutrition 101(1): 16-24.

Laurenius, Larsson I, Bueter M, Melanson KJ, Bosaeus I, Forslund HB, et al. (2012) Changes in eating behaviour and meal pattern following Roux-en-Y gastric bypass. International Journal of Obesity.36(3): 348-355.

Luiz LB, Brito DS, Debon M, Brandalise N, Azevedo JTD Monbach KD (2016) Variation of Binge Eating One Year after Roux- en-Y Gastric Bypass and Its Relationship with Excess Weight Loss. PLoS ONE 353:1-9.

Madura JA, Dibaise JK (2012) Quick fix or long-term cure ? Pros and cons of bariatric surgery. F 1000 Medicine Reports 9: 1-9.

Monpellier VM, Janssen IMC, Antoniou EE, Jansen ATM (2019) Weight Change After Roux-en Y Gastric Bypass, Physical Activity and Eating Style: Is There a Relationship? Obesity Surgery 29(2): $526-533$.

Naseri P, Majd HA, Kariman N, Sourtiji A (2016) Comparison of generalised estimating equation (GEE), mixed effects models (MEM) and repeated measure ANOVA in analysis of menorrhagia data. Journal of Paramedical Science 7(1): 32-40.

Nasirzadeh Y, Kantarovich K, Wnuk S, Okrainec A, Cassin SE, Hawa R, Sockalingam S (2018) Binge eating, loss of control over eating, emotional eating, and night eating after bariatric surgery: Results from the Toronto Bari-PSYCH cohort study. Obesity Surgery 28(7): 2032-2039.
Nicolau J, SImo R, Sanchis P, Ayala L, Fortuny R, Zubillaga I, Masmiquel L (2015) Eating disorders are frequent among type 2 diabetic patients and are associated with worse metabolic and psychological outcomes: results from a cross-sectional study in primary and secondary care settings. ActaDiabetologica 52(6): $1037-1044$

Nolan L, Geliebter A (2012) Night eating is associated with emotional and external eating in college students. Eating Behaviors13(3): 202-206.

Novelli IR, Fonseca LG, Lopes DG, Dutra ES, de Carvalho KMB (2017) Emotional eating behavior hinders body weight loss inwomen after roux-en-Y gastric bypass surgery. Nutrition 49:1316.

Odom J, Zalesin KC, Washington TL, Miller WW, Hakmeh B, Zaremba DL, Altattan M, Balasubramaniam M, Gibbs DS, Krause KR, Chengelis DL, Franklin BA, McCullough PA (2010) Behavioral predictors of weight regain after bariatric surgery. Obesity Surgery 20(3): 349-356.

Opolski M, Chur-Hansen A, Wittert G (2015) The eating-related behaviours, disorders and expectations of candidates for bariatric surgery. Clinical Obesity 5(4): 165-197.

Pinto-Bastos A, de Lourdes M, Brandão I, Machado PPP, Conceição EM (2019) Weight loss trajectories and psychobehavioral predictors of outcome of primary and reoperative bariatric surgery: a 2-year longitudinal study. Surgery for Obesity and Related Diseases 15(7): 1104-1112.

Quek KF, Atiya AS, Heng NGC, Beng CC (2007) Validation of the hospital anxiety and depression scale and the psychological disorder among premature ejaculation subjects. International Journal of Impotence Research 19(3):321-325.

Robinson AH, Adler S, Stevens HB, Darcy AM, Morton JM, Safer DL (2014) What variables are associated with successful weight loss outcomes for bariatric surgery after 1 year? Surgery for Obesity and Related Diseases 10 (4): 697-704

Sararaks S, Azman AB, Low LL, Rugayah BMAA, Hooi LN, Razak MA, et al. (2005) Validity and Reliability of the SF • 36 : The Malaysian Context. Malaysian Medical Journal 60(2): 163179.

Sevinc M, Cao L, Coskun H, Mitchell JE, Crosby RD, Mitchell JE (2016). Association between depression and eating behaviors among bariatric surgery candidates in a Turkish sample. Eating and Weight Disorders 22(1): 117-123. 
Sillén L, Andersson E, Andersson E (2017) Patient Factors Predicting Weight Loss after Roux-en-Y Gastric Bypass. Journal of Obesity 2017:3278751. doi: 10.1155/2017/3278751.

Sjostrom L (2013) Review of the key results from the Swedish Obese Subjects ( SOS ) trial - a prospective controlled intervention study of bariatric surgery. Journal of Internal Medicine 273: 219234.

Subramaniam K, Low WY, Chinna K, Chin K (2017) Psychometric Properties of the Malay Version of the Dutch Eating Behaviour Questionnaire ( DEBQ ) in a Sample of Malaysian Adults Attending a Health Care Facility. Malaysian Journal of Medical Science 4: 64-73.

Van Hout GCM, Jakimowicz JJ, Fortuin FM, Pelle AJM, van Heck GL (2007) Weight loss and eating behavior following vertical banded gastroplasty. Obesity Surgery 17(9): 1226-1234.

Van Strien T, Frijters JER, Bergers GP, Defares PB (1986) The Dutch Eating Behaviour Questionnaire (DEBQ) for assessment of restrained, emotional and external eating behaviour. International Journal of Eating Disorder 5(2): 295-315.

Ware JJ, Sherbourne C (1992) The MOS 36-item short-form health survey (SF-36). Conceptual frame work and Item Selection. Medical Care 30: 473-483.

White MA, Kalarchian MA, Masheb RM, Marsha D, Grilo CM (2010) Loss of control over eating predicts outcomes in bariatric surgery: A prospective 24-month follow-up study. Journal of ClincalPyschiatry 71(2): 175-184.

Wimmelmann CL, Dela F, Mortensen EL (2014) Psychological predictors of weight loss after bariatric surgery: A review of the recent research. Obesity Research \& Clinical Practice 8(4): e299e313.

Zigmond A, Snaith R (1983) The Hospital Anxiety and Depression Scale. ActaPsychiatrica Scandinavia 67: 361-370. 